\title{
$\mathrm{PH} 96_{\text {bienes, paisajes e itinerarios }}$
}

\section{Panorama actual de la arqueología urbana en Huelva}

Juan M. Campos Carrasco | Dpto. de Historia I de la Universidad de Huelva

URL de la contribución <www.iaph.es/revistaph/index.php/revistaph/issue/view/4290>

\section{RESUMEN}

En esta contribución ${ }^{1}$ se presenta un panorama general de la arqueología urbana en la ciudad portuaria de Huelva. Se analizan las diferentes etapas, marcadas por distintos intereses, metodologías y mecanismos de gestión, por las que han transcurrido las intervenciones arqueológicas en la ciudad desde el año 1966 hasta el presente, que ascienden a 324, para a partir de ahí realizar un balance de los resultados, analizar la situación actual y reflexionar sobre un proyecto de futuro que permita el rescate y la reconstrucción de la memoria histórica de la ciudad de Huelva. Proyecto que ha de desarrollarse en el marco de diálogo entre los ciudadanos, ávidos de conocer su pasado, los agentes de desarrollo inmobiliario, generadores de riqueza y progreso, la Universidad, garante de la investigación, y los poderes públicos, responsables de garantizar el futuro del pasado.

Palabras clave

Arqueología urbana | Onoba | Huelva | Patrimonio arqueológico | Tarteso | 


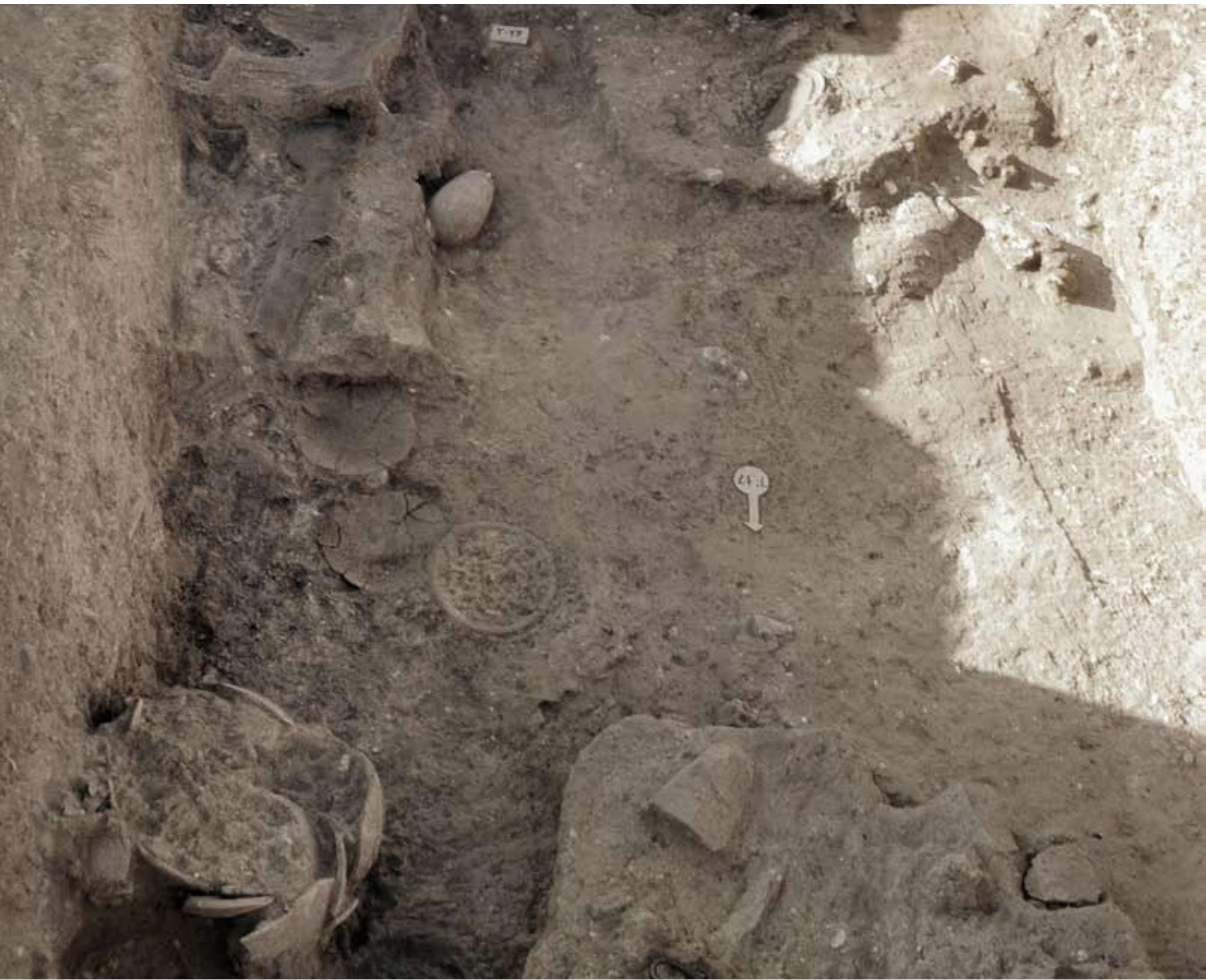

Excavación de la tumba 17 de La Joya | fuente LÓPEZ; GARCíA, 2010 


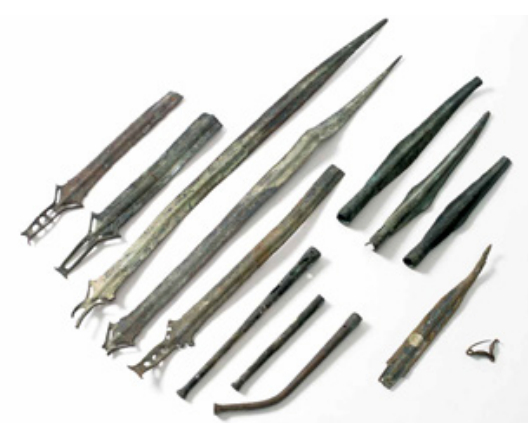

Bronces encontrados en la ría de Huelva | fuente TOSCANO; CAMPOS, 2018

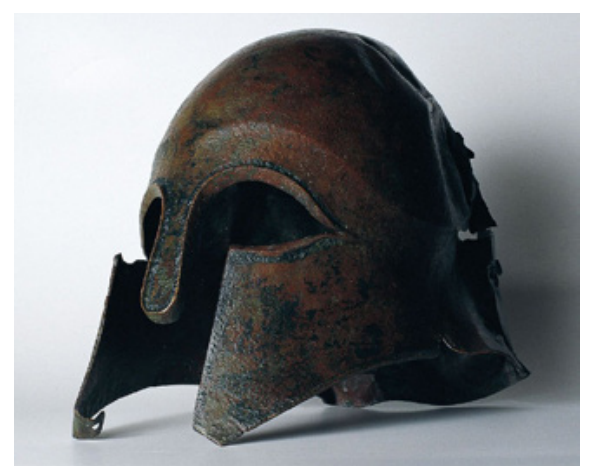

Casco corintio de la ría de Huelva | fuente ALMAGRO-GORBEA; CASADO; FONTES et ál., 2004

1

El presente trabajo se enmarca dentro de las actividades del Proyecto de Investigación de Excelencia del Plan Andaluz de Investigación Ciudades Romanas de la Bética. CORPVS VRBIVM BAETICARVM I (Ref. HUM 2062) y del proyecto del Plan Nacional de I+D De Atlántico al Tirreno ( $2^{\mathrm{a}}$ fase). Los puertos hispanos y su relación comercial con Ostia Antica (HAR2014-58326-P).

\section{INTRODUCCIÓN}

El descubrimiento en 1923 de un lote de bronces en el dragado de la ría de Huelva (ALMAGRO BASCH, 1940; 1957), al que años más tarde se unen un casco y un fragmento de aryballos corintios (ALBELDA; OBERMAIER, 1931; OLMOS ROMERA, 1988; ROUILLARD, 1978) despertaron la curiosidad de la comunidad científica, acrecentada por el descubrimiento en 1945 de una tumba en el cabezo de la Joya, cuya publicación casi veinte años después (ORTA GARCÍA; GARRIDO ROIZ, 1963) estableció una inmediata relación de Huelva con Tarteso, en un ambiente que volvía a ser propicio para la reanudación de la búsqueda de la legendaria ciudad, por los nuevos hallazgos que se estaban produciendo en el resto de Andalucía (MALUQUER DE MOTES, 1969).

Pero no será hasta mediados de los años 60 del pasado siglo cuando, de la mano de los profesores Juan Pedro Garrido y Elena M. ${ }^{\text {a }}$ Orta, comienzan las primeras intervenciones arqueológicas en la ciudad, en los cabezos de la Esperanza y La Joya. Desde entonces hasta hoy se han producido 324 intervenciones que hacen que el yacimiento de Huelva sea el más excavado de la provincia.

\section{LAS INTERVENCIONES EN LA CIUDAD}

El conjunto de intervenciones arqueológicas antes señalado puede considerarse muy desigual, según el momento de que se trate, pudiendo distinguirse varias etapas marcadas por diferentes intereses, metodologías y mecanismos de gestión que a continuación sintetizamos.

La primera etapa, caracterizada por la búsqueda de Tarteso, se desarrollará entre 1966 y 1971. Supone el comienzo de las primeras excavaciones en la ciudad realizadas por diversos equipos de la Universidad Complutense de Madrid. La importancia del hábitat protohistórico de Huelva, a partir de la publicación de la tumba orientalizante de La Joya (ORTA GARCíA; GARRIDO ROIZ, 1963), propició la búsqueda de otros enterramientos que correspondiesen a la misma u otras necrópolis, ubicadas en la ciudad. De esta forma, en la necrópolis de La Joya, en sucesivas campañas de verano, se excavaron varias tumbas en la superficie del cabezo cuyos ajuares las fecharon entre finales del siglo VII y comienzos del VI a. de C. (ORTA GARCÍA; GARRIDO ROIZ, 1963; GARRIDO ROIZ, 1970; GARRIDO ROIZ; ORTA GARCíA, 1978; 1989). El hábitat sincrónico a estas tumbas sería buscado inicialmente en los cabezos de La Esperanza (GARRIDO; ORTA, 1969; SCHUBART; GARRIDO ROIZ, 1967; BELÉN DEAMOS; FERNÁNDEZMIRANDA; GARRIDO ROIZ, 1978). En 1968, en unos trabajos de desmonte que se estaban realizando en el cabezo de San Pedro, aparecieron niveles 


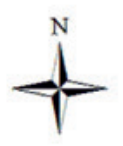

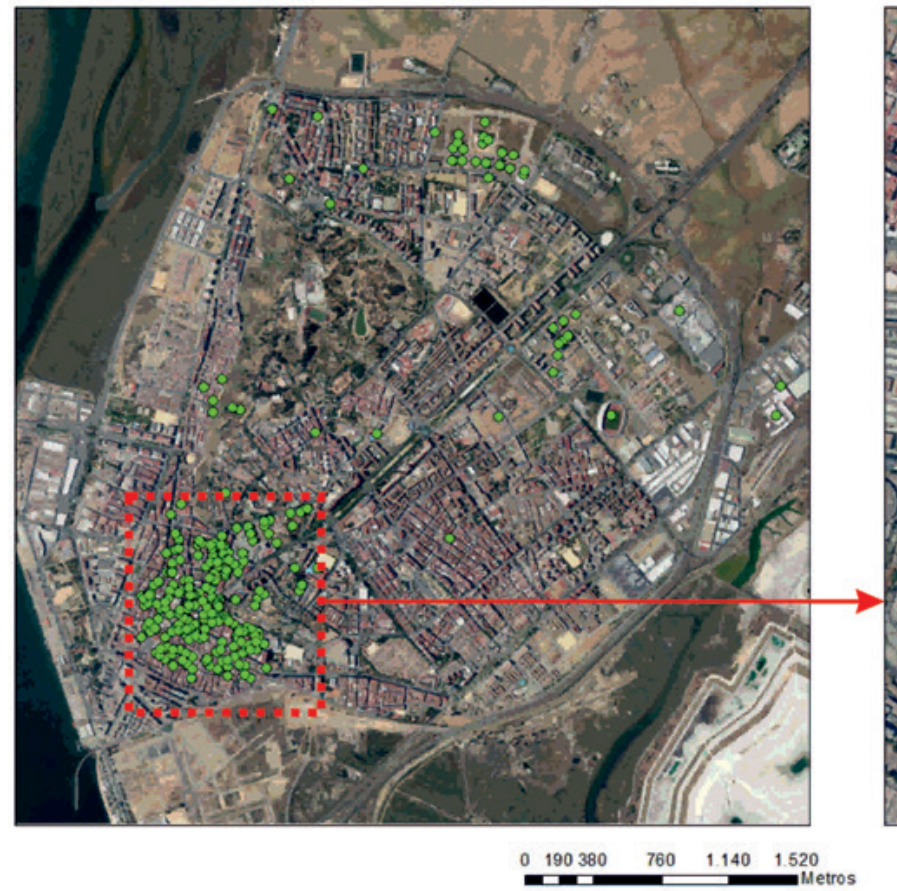

arqueológicos de amplia cronología estableciéndose una primera sistematización de la ocupación del lugar (BLÁZQUEZ MARTíNEZ; LUZÓN NOGUÉ; GÓMEZ et ál., 1970). Como resultado de todas estas intervenciones realizadas sobre los cabezos de la Joya y La Esperanza, que ascendieron a 10, se elabora una primera sistematización del poblamiento prerromano de Huelva, dividido en amplios períodos, desde el más antiguo, Huelva I, indígena aunque con escasas importaciones fenicias, hasta Huelva $\mathrm{VI}$, que significaba el comienzo de la romanización del hábitat situado en los cabezos (AMO Y DE LA HERA; BELÉN DEAMOS, 1981).

Entre 1972 y 1976 se identifica una segunda etapa, protagonizada por el Museo de Huelva, que pone al descubierto restos romanos de la Onoba romana (AMO Y DE LA HERA, 1976).

A partir de 1977 y hasta 1981 se desarrolla una tercera etapa caracterizada por la vuelta a la arqueología tartésica. El siguiente equipo que excavará en la cima de San Pedro (BLÁZQUEZ MARTíNEZ; RUIZ MATA; REMESAL RODRÍGUEZ et ál., 1979; RUIZ MATA; BLÁZQUEZ MARTÍNEZ; MARTÍN DE LA CRUZ, 1981) alcanzó unos resultados que con matizaciones pueden ser considerados todavía vigentes (RUIZ MATA, 1986; 1995). En el

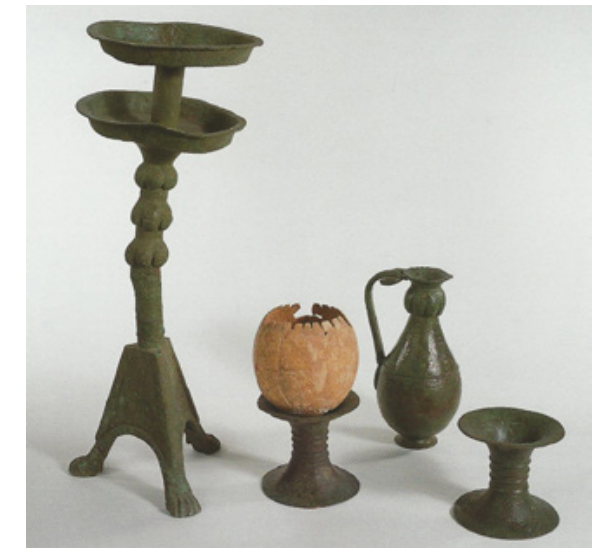

Ajuar de la tumba 17 de La Joya | fuente GARCíA ALFONSO, 2010 


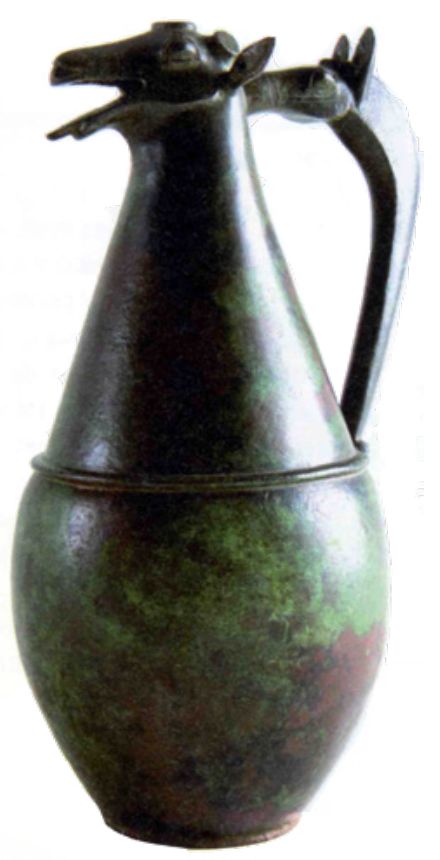

Ajuar de la tumba 18 de la Joya | fuente VALLEJO SÁNCHEZ, 2010

A la derecha, plano de los restos de la cetaria de Huelva | fuente AMO Y DE LA HERA, 1976
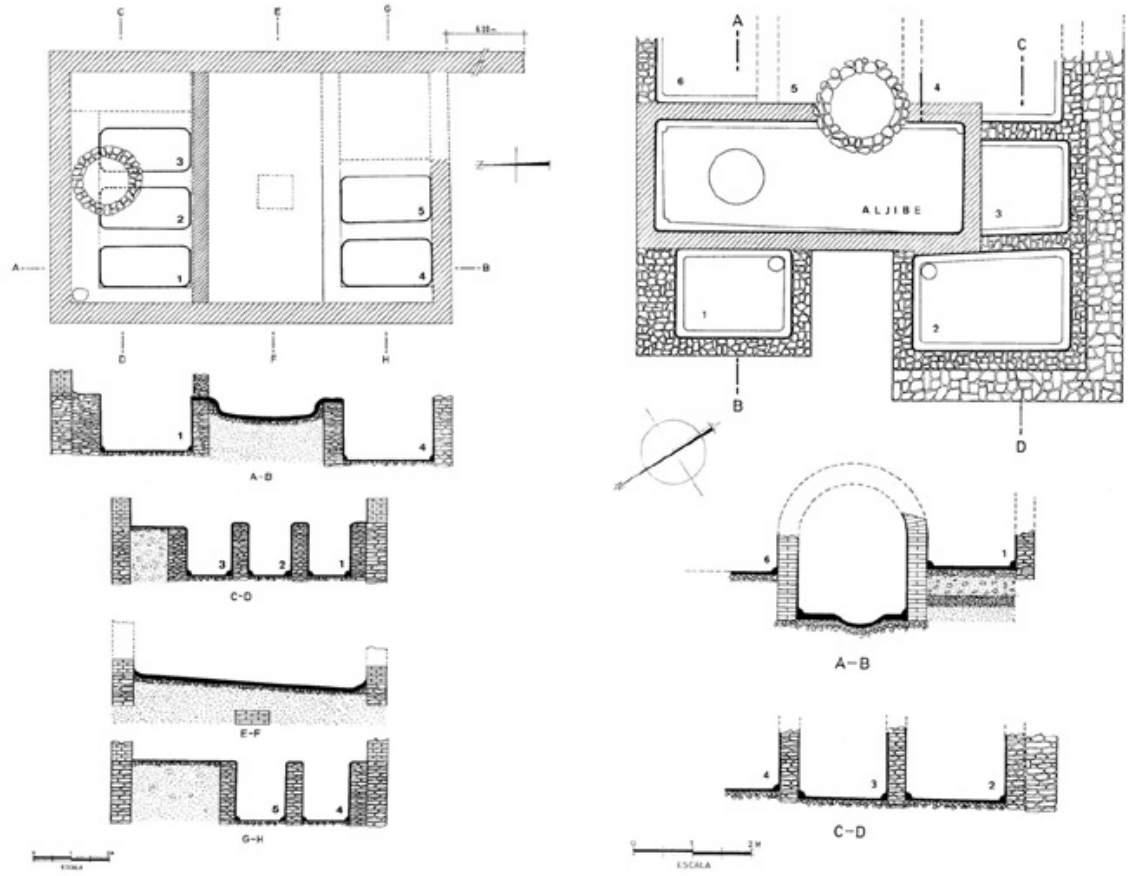

verano de 1980 se realizan algunos sondeos en el solar número 10 de la calle del Puerto. Como resultado, surgen diversos artículos donde se pone el énfasis en las cerámicas griegas arcaicas localizadas (OLMOS ROMERA; CABRERA BONET, 1980; OLMOS ROMERA, 1982; CABRERA BONET, 1986; FERNÁNDEZ JURADO; CABRERA BONET, 1987; GARRIDO ROIZ; ORTA GARCÍA, 1989), que suponen una novedad importante para retomar los planteamientos que se relacionaban con la presencia de los griegos en Tarteso, y que provocarán, en última instancia, que prácticamente se abandone la investigación del período romano y otros posteriores.

Durante casi toda la década de los 80 y 90 se desarrolla la cuarta etapa. Será el equipo de la Diputación Provincial de Huelva el que protagonice, salvo contadísimas excepciones, las excavaciones en la ciudad al amparo del modificado del artículo 104 del Plan General de Ordenación Urbana de 1980. Científicamente, en esta etapa continúa el interés preferencial por el mundo tartésico en detrimento del mundo romano, medieval y moderno. Queda, sin embargo, un número importante de publicaciones, tanto de carácter científico (FERNÁNDEZ JURADO, 1988-1989; FERNÁNDEZ JURADO; RUFETE TOMICO; GARCÍA SANZ, 1992) como divulgativo (FERNÁNDEZ JURADO; GARCÍA SANZ; RUFETE TOMICO, 1997; RUFETE TOMICO; GARCÍA SANZ, 1995), que constituyen un importantísimo corpus de información para el conocimiento de la arqueología onubense, en especial el periodo protohistórico. 
Finalmente, la etapa actual comienza a partir de 1999. La incoación del expediente de Declaración de la zona arqueológica de Huelva cambia radicalmente el panorama anteriormente descrito provocando una nueva política patrimonial para las excavaciones arqueológicas que se realizan en el casco antiguo de Huelva y que, entre otras cosas, conlleva un tratamiento diferente de otros periodos históricos. Una de las consecuencias más destacable ha sido la gran revitalización de la Onoba romana, cuyos restos materiales están viendo la luz de forma más intensa en los últimos años, permitiendo incluso las reconstrucciones virtuales de algunos de los espacios excavados, en especial la zona portuaria (CAMPOS CARRASCO, 2001-2002; 2011; VIDAL; CAMPOS, 2006; CAMPOS CARRASCO; BERMEJO MELÉNDEZ, 2017; DELGADO AGUILAR, 2016; BERMEJO MELÉNDEZ; CAMPOS CARRASCO; RODRÍGUEZ-VIDAL, 2017). Esta nueva realidad se cimenta en dos hechos fundamentales: el aumento del número de intervenciones, unas 220 desde entonces hasta hoy, y la incorporación a las intervenciones de la Universidad de Huelva y de empresas profesionales de arqueología.

Desde fines de 2016 hasta hoy, aunque interrumpido durante casi todo el año 2018, se ha desarrollado un Plan General de Investigación de la zona arqueológica de Huelva, como transición hacia un verdadero proyecto de arqueología urbana, gracias al protocolo firmado entre la Consejería de Cultura de la Junta de Andalucía y la Universidad de Huelva. La finalidad principal es la recuperación e integración de la información arqueológica derivada de las actividades arqueológicas desarrolladas en la ciudad, cuyos materiales se encuentran depositados en el Museo de Huelva. Paralelamente se están realizando diagnósticos de los diversos sectores que conforman la zona arqueológica. Finalmente se está actualizando la carta de riesgo mediante la incorporación en un SIG de toda la información que se va generando así como de las nuevas intervenciones que se producen en la ciudad (CAMPOS CARRASCO, 2016).

Es dentro de esta tendencia de apertura donde hay que valorar el avance producido en la investigación arqueológica de este yacimiento, y especialmente en lo que se refiere a su horizonte romano, carente hasta el momento de una interpretación conjunta de los distintos aspectos que lo integran.

\section{BALANCE DE LAS INTERVENCIONES}

La actividad arqueológica en la ciudad de Huelva, desde los inicios de las primeras intervenciones en 1966 hasta hoy, ofrece luces y sombras, pudiendo destacar las siguientes cuestiones:

Desde el punto de vista de la metodología aplicada, la primera cuestión a señalar, en consecuencia con lo anteriormente expuesto, es el hecho de que

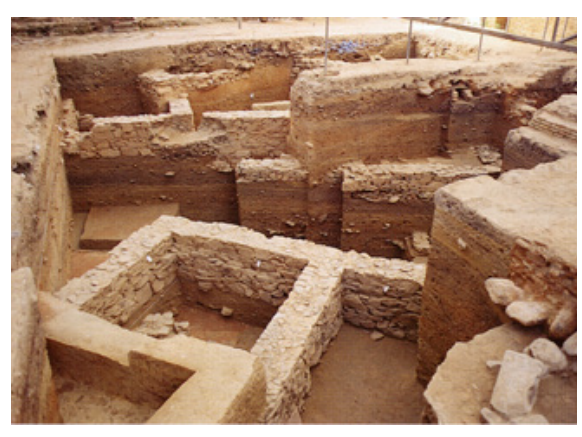

Restos protohistóricos hallados en la C/ Puerto, 12 | fuente RUFETE TOMICO; GARCÍA SANZ, 1995

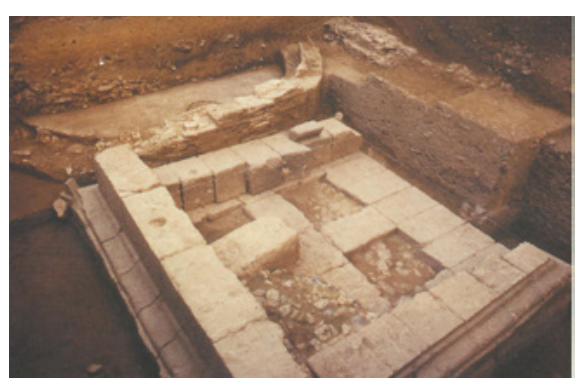

Basamento romano. Convento de las Agustinas | fuente FERNÁNDEZ JURADO; GARCÍA SANZ; RUFETE TOMICO, 1997 

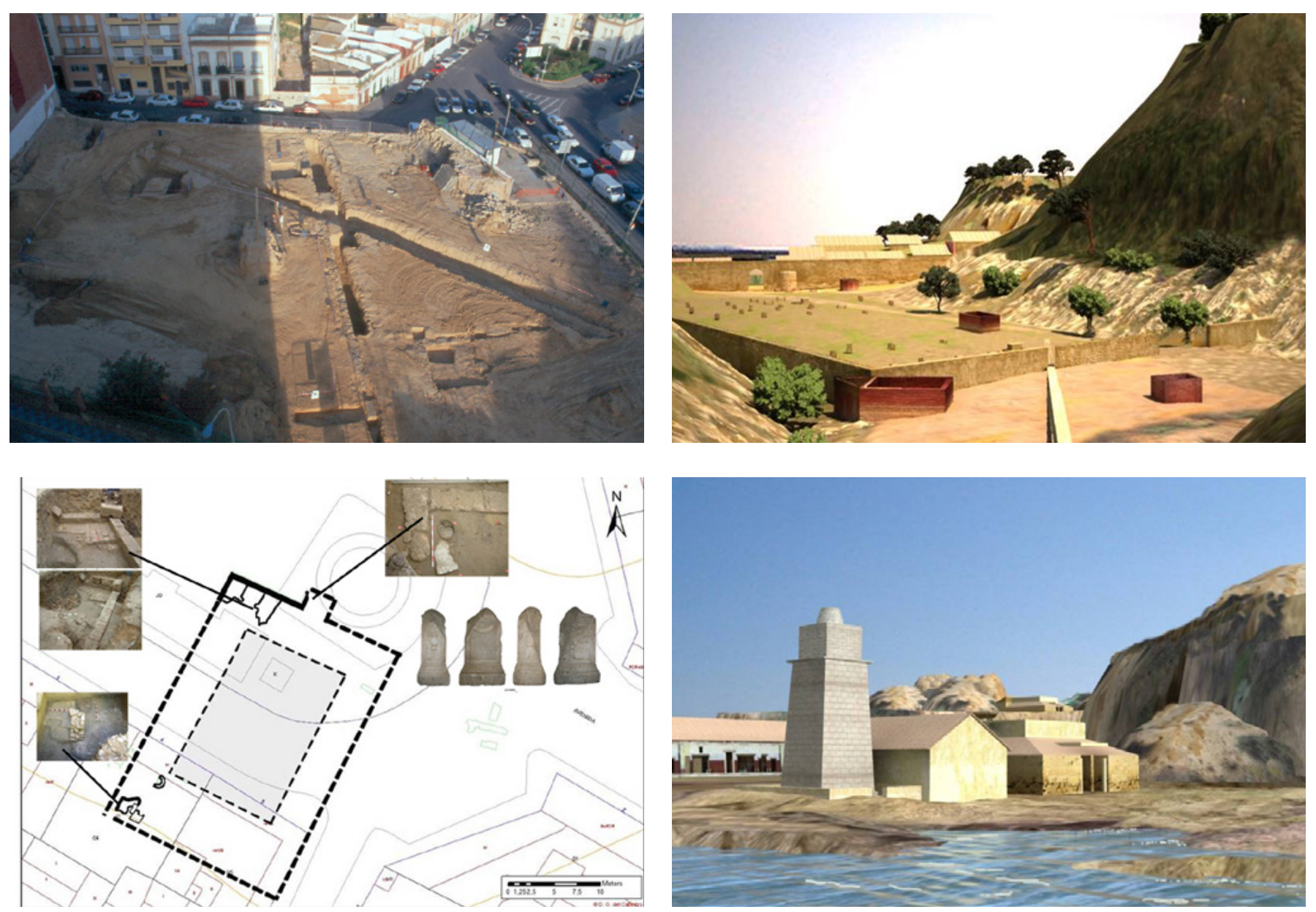

Arriba a la izquierda, necrópolis romana del Colegio Francés

Arriba a la derecha, reconstrucción infográfica de la necrópolis del Colegio Francés

Abajo a la izquierda, restitución del edificio romano de sillares de plaza de las Monjas

Abajo a la derecha, restitución infográfica de la zona portuaria y faro de Onoba | foto, esquema e infografías Grupo de Investigación Vrbanitas Arqueología y Patrimonio el conjunto de las intervenciones no ha estado presidido nunca por un verdadero proyecto de arqueología urbana, limitándose al concepto de intervenciones en medio urbano que difiere notablemente de aquél. La ausencia de un proyecto de ciudad ha impedido, hasta el momento, una síntesis del conjunto del poblamiento y su evolución desde los inicios de la ocupación del espacio, desde la prehistoria hasta la actualidad. Por otro lado, han sido muy diferentes los métodos de excavación puestos en práctica y los planteamientos científicos para la interpretación del registro arqueológico. Por último, y referido a los tiempos presentes, hay que señalar que el hecho de que las actuaciones sean realizadas por diferentes empresas de arqueología dificulta la incorporación de los datos a un proyecto general de investigación, basado en el concepto de arqueología urbana o, al menos, la fluidez de los mismos al banco de datos ya existente en la carta de riesgo, que debería estar siempre actualizado, si se quiere disponer de una herramienta útil tanto para la gestión del patrimonio arqueológico de la ciudad, como para su investigación histórico-arqueológica. El desarrollo del actual 
Plan General de Investigación vigente intenta paliar en parte los problemas señalados.

En cuanto a la orientación de las intervenciones, como ya se ha puesto de manifiesto, salvo el caso de las realizadas por el Museo Provincial a principios de los años 70, el interés de la investigación se centró casi con exclusividad en el mundo tartésico. Esta tendencia ha cambiado notablemente en la etapa que comenzó a fines de los años 90 dándose una mayor importancia a otros periodos históricos que ha contribuido a enriquecer de manera muy notable el conocimiento histórico de la Huelva romana, medieval y moderna.

En relación con lo anterior, el rendimiento científico ha estado muy determinado por esa orientación de forma que el nivel de publicaciones referidas a la etapa protohistórica era abrumadoramente mayor que el de otros periodos históricos. Sólo en los últimos años se ha avanzado en el conocimiento de otras manifestaciones históricas, especialmente el mundo romano. En cualquier caso, el nivel global de interpretación elaborado no se corresponde con el volumen de datos disponibles, según hemos justificado en La Carta de Riesgo de Huelva (CAMPOS; GÓMEZ; LÓPEZ, 2000) y en la, hasta ahora, única síntesis histórico-arqueológica que realiza la puesta al día del conjunto de datos conocidos (GÓMEZ TOSCANO; CAMPOS CARRASCO, 2001).

Pero sin duda, el cambio más significativo se ha producido en la gestión de las intervenciones urbanas. A partir de 1999, como se ha señalado, cambia radicalmente el panorama anteriormente descrito. La redacción de la Carta de Riesgo de la Ciudad de Huelva permitió la elaboración del expediente de incoación de la zona arqueológica de Huelva con una nueva delimitación que perfila una zona arqueológica mucho más amplia y compleja que la contemplada en el PGOU de 1980, estableciendo ámbitos precisos de protección teniendo en cuenta el diagnóstico previo establecido en la Carta de Riesgo del Casco Antiguo de la Ciudad de Huelva y las nuevas experiencias adquiridas en los últimos años. Esto conlleva un nuevo procedimiento que consiste en que a la financiación pública, tanto municipal como autonómica, de las diferentes actuaciones arqueológicas, se incorporan los promotores privados que han de sufragar los costes de las intervenciones arqueológicas en las obras que promueven.

Siguiendo este procedimiento, desde noviembre de 1999, como ya se ha indicado, se han realizado unas 220 excavaciones y seguimientos arqueológicos de diverso alcance que han permitido establecer diferentes acciones encaminadas a la protección, conservación, revalorización y difusión del patrimonio histórico-arqueológico de la ciudad de Huelva.

Finalmente, y relacionado con lo anterior, en lo que a la conservación de restos se refiere, la referida Declaración también establece un punto de inflexión 

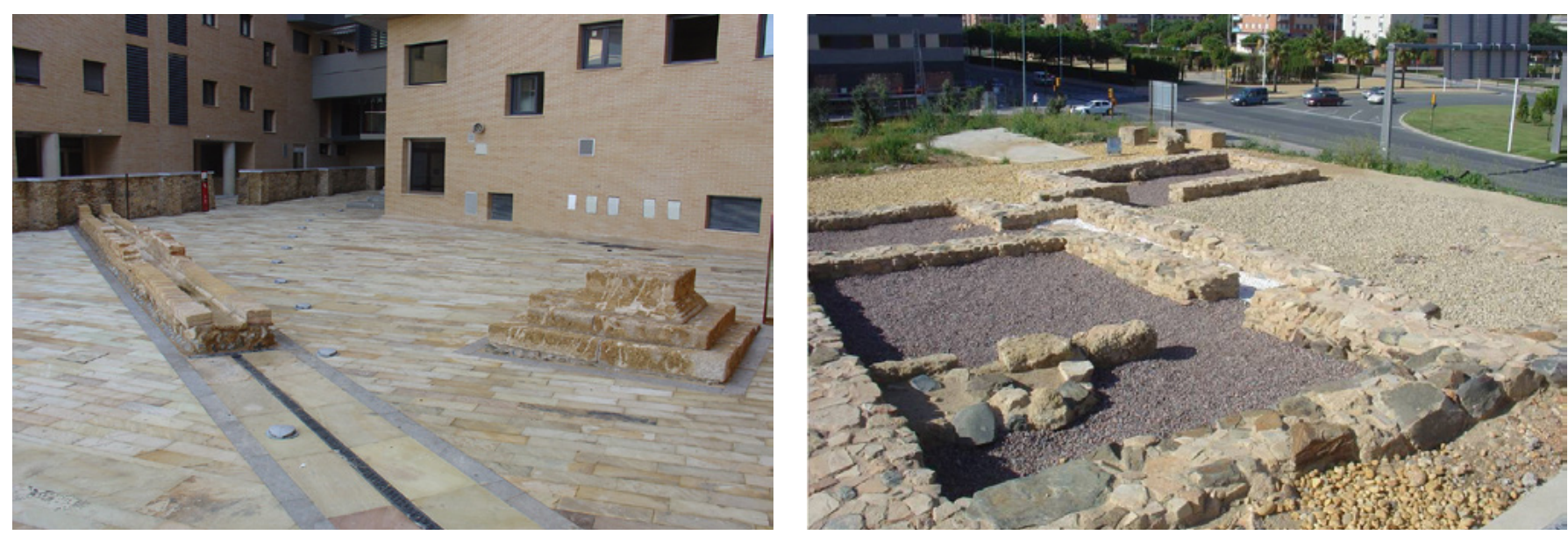

A la izquierda, puesta en valor de la necrópolis del Colegio Francés

A la derecha, puesta en valor de la villa romana de La Almagra | fotos Grupo de Investigación Vrbanitas Arqueología y Patrimonio en este aspecto, pues salvo los restos del conocido Muro de San Pedro, conservado por iniciativa privada, nada se había conservado en la ciudad hasta ese momento, lo que ha supuesto la destrucción de una muestra significativa de restos para comprender la evolución histórica de la ciudad. En los últimos años han sido varias las iniciativas orientadas hacia la conservación y difusión de restos, como son los casos de la calle Arquitecto Pérez Carasa, plaza de San Pedro, antiguo Colegio Francés, villa de La Almagra y Parque Moret. A pesar de ello, creemos que es todavía una asignatura pendiente que la ciudad en su conjunto debe superar con una apuesta más decidida a la hora de tomar decisiones sobre la integración de restos.

\section{LAS PERSPECTIVAS DE FUTURO}

Sin duda, el futuro de la investigación en la ciudad de Huelva pasa por, superando el actual Plan General de Investigación, el diseño de un proyecto de ciudad, donde la arqueología urbana se posicione como una actividad fundamental. El hecho de tratarse de un enclave que se extiende desde los albores del I milenio a. de C. hasta nuestros días sin solución de continuidad y de presentar un alto grado de conservación, no sólo del registro arqueológico sino también de los restos inmuebles, otorga al proyecto un alto valor en lo que al desarrollo cultural y turístico de la ciudad se refiere.

Por otro lado, los beneficios de una investigación de estas características podrían ser aprovechados por la propia dinámica de planeamiento y administración urbanística del ente local mediante la actualización continua de la carta de riesgo.

Con todas las premisas anteriores, la existencia de un proyecto general de arqueología urbana en la zona arqueológica de Huelva, de acuerdo con las 
evidencias mostradas en apartados anteriores, encuentra su más lógica justificación, tanto desde la perspectiva de la gestión del patrimonio histórico de la ciudad por las instituciones responsables de su protección y difusión, como desde las que asuman su investigación y divulgación científica.

Con este proyecto se puede aglutinar la información que se genere en las diversas actuaciones arqueológicas que se realicen en un futuro, cuyo fin, al estar fundamentalmente encaminado al diagnóstico patrimonial de zonas o parcelas urbanas, podría perder el necesario componente histórico-científico que debe presidir la investigación que se lleve a cabo en el ámbito de una ciudad superpuesta como Huelva.

Por otra parte, dado que las intervenciones en la ciudad están garantizadas con las figuras de protección necesarias, un proyecto de arqueología urbana representaría poner en práctica una tendencia que, de acuerdo con la experiencia adquirida en la Comunidad Autónoma de Andalucía en los últimos años, parece la culminación de un modelo de gestión del patrimonio histórico-arqueológico imprescindible en este milenio.

Desde esta perspectiva, serán pues los dos mecanismos citados, la Declaración de Huelva como zona arqueológica, y la redacción de la carta de riesgo, incluidas en el Plan General de Ordenación Urbana, los que faculten un nuevo marco de diálogo entre los ciudadanos, ávidos de conocer su pasado, los agentes de desarrollo inmobiliario, generadores de riqueza y progreso, la Universidad, garante de la investigación, y los poderes públicos, responsables de garantizar el futuro del pasado. Confluyen, de este modo, toda la diversa gama de esfuerzos en planificación e intervención de facto sobre la ciudad, y es en este plano de confluencia donde se pone de manifiesto el carácter sintético y dinámico del problema urbano: la ciudad histórica como proyecto en continuo desarrollo.

Las relaciones actuales entre planeamiento urbanístico, intervención arquitectónica en el patrimonio inmobiliario y arqueología preventiva y sistemática, nos llevan a la consideración de la ciudad histórica como objeto proyectual, donde desde el concepto de arqueología urbana se integraría de forma plena en lo que hemos llamado el proyecto ciudad. Pero esta integración, sin dudas, pasa necesariamente, como se ha defendido, por la articulación de un proyecto general de investigación de futuro donde, respetando la libertad científica de los diferentes investigadores o profesionales de la arqueología que lleven a cabo las intervenciones de urgencia, se pueda generar y procesar el volumen de información obtenida mediante registros homologados, que permita el rescate y la reconstrucción de la memoria histórica de la ciudad de Huelva (CAMPOS; VIDAL, 2013). 


\section{BIBLIOGRAFÍA}

- AlBELDA, J.; OBERMAIER, H. (1931) El casco griego de Huelva. Boletín de la Real Academia de la Historia, tomo 98, cuaderno II (abril-junio, 1931), pp. 642-648

- ALMAGRO BASCH, M. (1940) El hallazgo de la ría de Huelva y el final de la Edad del Bronce en el Occidente de Europa. Ampvrias. Revista de Arqueología, Prehistoria y Etnografía, II, 1940, pp. 85-143

- ALMAGRO BASCH, M. (1957) Las fíbulas de codo de la ría de Huelva. Su origen y cronología. Cuadernos de trabajo de la Escuela Española de Historia y Arqueología en Roma, n. ${ }^{\circ}$ 9, 1957, pp. 7-46

- ALMAGRO-GORBEA, M.; CASADO, D.; FONTES, F.; MEDEROS, A.; TORRES, M. (2004) Casco corintio de la Ría de Huelva. En ALMAGRO-GORBEA, M.; CASADO, D.; FONTES, F.; MEDEROS, A.; TORRES, M. Catálogo del Gabinete de Antigüedades de la Real Academia de la Historia. Prehistoria. Antigüedades Españolas I. Madrid: Real Academia de Historia, 2004, pp. 174-176

- AMO Y DE LA HERA, M. DEL; BELÉN DEAMOS, M. (1981) Estudio de un corte estratigráfico en el Cabezo de San Pedro. Huelva Arqueológica, n. ${ }^{\circ}$ 5, 1981, pp. 57-148

- AMO Y DE LA HERA, M. DEL (1976) Restos materiales de la población romana de Onuba. Huelva Arqueológica, n. ${ }^{\circ} 2,1976$, pp. 11-196

- BELÉN DEAMOS, M.; FERNÁNDEZ-MIRANDA, M.; GARRIDO ROIZ, J. P. (1977) Los orígenes de Huelva: excavaciones en los Cabezos de San Pedro y La Esperanza. Huelva Arqueológica, n. ${ }^{0} 3,1977$, pp. 13-171

- BERMEJO MELÉNDEZ, J.; CAMPOS CARRASCO, J. M.; RODRÍGUEZ-VIDAL, J. (2017) Las estructuras portuarias de Onoba Aestuaria: Un puerto pesquero y de control imperial. En CAMPOS CARRASCO, J. M.; BERMEJO MELÉNDEZ, J. (ed.) Los Puertos Atlánticos Béticos y Lusitanos y su relación comercial con el Mediterráneo. Roma: “L’Erma" di Bretschneide, 2017, pp. 207-243 (Hispania Antigua-Serie Arqueologica)

- BLÁZQUEZ MARTÍNEZ, J. M.; LUZÓN NOGUÉ, J. M.; GÓMEZ, F.; CLAUSS, K. (1970) Huelva Arqueológica. Las cerámicas del Cabezo de San Pedro. Huelva: Diputación Provincial de Huelva, 1970

- BLÁZQUEZ MARTÍNEZ, J. M.; RUIZ MATA, D.; REMESAL RODRÍGUEZ, J.; RAMÍREZ SÁDABA, J. L.; CLAUSS, K. (1979) Excavaciones en el Cabezo de San Pedro (Huelva). Campaña de 1977. Madrid: Ministerio de cultura. Dirección General del Patrimonio Artístico, Archivos y Museos. Subdirección General de Arqueología, 1979 (Excavaciones Arqueológicas en España, 102)

- CABRERA BONET, P. (1986) La presencia griega en Huelva: los materiales griegos. Homenaje a Luis Siret (1934-1984). Sevilla: Consejería de Cultura, pp. 575-583
- CAMPOS CARRASCO, J. M. (2001-2002) La ciudad romana de Onuba (Huelva). Una revisión arqueológica. Anales de Prehistoria y Arqueología, n. ${ }^{\circ}$ 17-18, 2001-2002, pp. 329-340

- CAMPOS CARRASCO, J. M. (2006) Huelva, desde los inicios hasta la Edad Media. En LARA RÓDENAS, M. J. DE; ECHENAGUSIA BELDA, J.; ORTEGA, C.; CAMPOS CARRASCO, J. M. Huelva. Barcelona: Editorial Lunwerg, 2006, pp. 13-25

- CAMPOS CARRASCO, J. M. (2011) Onoba Aestuaria. Una ciudad portuaria en los confines de la Baetica. Huelva: Ayuntamiento, Concejalía de Cultura, 2009

- CAmpos CARRAsco, J. M. (2016) Plan General de investigación arqueológica: Zona Arqueológica de Huelva. Consejería de Cultura. Junta de Andalucía. Inédito

- CAMPOS CARRASCO, J. M.; BERMEJO MELÉNDEZ, J. (2017) Los suburbios de Onoba Aestuaria, el área portuaria. En PANZRAM, S. OPPIDIUM-CIVITAS-URBS. Stadteforschung auf der Iberischen Halbinsel Zwischen Rom und al-Andalus. Berlín: LIT Verlag, 2017, pp. 739-766

- CAMPOS, J. M.; GÓMEZ, F.; LÓPEZ, M. A. (2000) Carta de Riesgo de la Ciudad de Huelva. Excmo. Ayuntamiento de Huelva. Inédita

- CAMPOS, J. M.; VIDAL, N. O. (2013) Arqueología urbana en Huelva: balance y perspectivas de futuro. En GÓMEZ TOSCANO, F. Arqueología en la Provincia de Huelva: homenaje a Javier Rastrojo Lunar. Huelva: Servicio de Publicaciones Universidad de Huelva, Asociación Profesional de Arqueólogos de la Provincia de Huelva, 2013, pp. 27-36

- DElgado Aguilar, S. (2016) Onoba Aestuaria [en línea]. Tesis doctoral inédita. Universidad de Huelva, 2016 <http://rabida.uhu.es/dspace/handle/10272/12086> [Consulta: 08/11/2018]

- FERNÁNDEZ JURADO, J. (1988-1989) Tartessos y Huelva. Huelva Arqueológica, n. ${ }^{\circ}$ 10-11 (1), 1988-1989

- FERNÁNDEZ JURADO, J.; RUFETE TOMICO, P.; GARCÍA SANZ, C. (1992) Análisis y definición de la cultura tartésica según Tejada la Vieja (Escacena) y Huelva. Síntesis de resultados. En CAMPOS CARRASCO, J. M.; NOCETE CALVO, F. (coord.) Investigaciones Arqueológicas en Andalucía (1985-1992). Proyectos. Huelva, pp. 79-85 y 497-499

- FERNÁNDEZ JURADO, J.; CABRERA BONET, P. (1987) "Comercio griego en Huelva a fines del siglo $V$ a.C." Simposio Internacional Grecs et Ibères au IVè siècle $a$. J. C. Revue d'Etudes Anciens, tomo 89, n. ${ }^{\circ} 3-4,1987$, pp. 149-159

- FERNÁNDEZ JURADO, J.; GARCÍA SANZ, C.; RUFETE TOMICO, P. (1997) De Tartessos a Onuba. 15 años de 
arqueología en Huelva. Huelva: Diputación Provincial de Huelva, 1997

- gARCíA ALFONSO, E. (2010) Elementos de carro. En LÓPEZ, M. D.; GARCÍA, E. (ed.) Cádiz y Huelva. Puertos Fenicios del Atlántico. Sevilla: Fundación Cajasol, Junta de Andalucía, 2010, pp. 302-303

- GARRIDO ROIZ, J. P.; ORTA GARCíA, M. E. (1969) Cerámicas prerromanas de Huelva. Trabajos de Prehistoria, 26, 1969, pp. 327-335

- GARRIDO ROIZ, J. P. (1970) Excavaciones en la necrópolis de la Joya (1. a y 2. ${ }^{a}$ campañas). Madrid: Ministerio de Educación y Ciencia. Dirección General de Bellas Artes, Comisaría General de Excavaciones Arqueológicas, 1970 (Excavaciones Arqueológicas en España, 71)

- GARRIDO ROIZ, J. P.; ORTA GARCíA, E. M. (1978) Excavaciones en la necrópolis de La Joya, Huelva II. $\left(3^{a}, 4^{a}\right.$ y $5^{a}$ Campañas). Madrid: Ministerio de Educación y Ciencia. Dirección General de Bellas Artes, Comisaría General de Excavaciones Arqueológicas, 1970-1978 (Excavaciones Arqueológicas en España, 96)

- GARRIDO ROIZ, J. P.; ORTA GARCíA, M. E. (1989) La necrópolis y el hábitat orientalizante de Huelva. Itinerarios de Monumentos. Huelva: Consejería de Cultura, Delegación Provicial de Huelva, 1989, pp. 5-93

- gÓMEz toscano, F.; CAMPos CARRASCO, J. M. (2001) Arqueología en la Ciudad de Huelva (1966-2000). Huelva: Universidad, 2001

- LÓPEZ, M. D.; GARCíA, E. (eds.) (2010) Cádiz y Huelva. Puertos Fenicios del Atlántico. Sevilla: Fundación Cajasol, Junta de Andalucía, 2010

- MALUQUeR DE MOTES, J. (1969) Tartessos y sus problemas: Actas del V Symposium Internacional de Prehistoria Peninsular (Jerez de la Frontera. 1968). Barcelona: Universidad de Barcelona, 1969

- OlMOS ROMERA, R. (1982) La cerámica griega en el Sur de la Península Ibérica. La aportación de Huelva. La Parola del Passato, n. ${ }^{\circ}$ 37, 1982, pp. 393-406

- OlMOS ROMERA, R. (1988) El casco griego de Huelva. Clásicos de la arqueología de Huelva, n. ${ }^{\circ} 1,1988$, pp. 3778

- OlMOS ROMERA, R.; CABRERA BONET, P. (1980) Nuevo fragmento de Clitias en Huelva. Archivo Español de Arqueología, vol. 53, n. ${ }^{\circ}$ 141-142, 1980, pp. 5-14

- ORTA gARCÍA, E. M.; GARRIDO ROIZ, J. P. (1963) La tumba orientalizante de la Joya, Huelva. Madrid: Consejo Superior de Investigaciones Científicas, Instituto Español de Prehistoria (Trabajos de Prehistoria, XI)

- ROUILLARD, P. (1978) Fragmentos griegos de estilo geométrico y corintio medio en Huelva. Huelva Arqueológica, III, 1978, pp. 397-401

- RUFETE TOMICO, P.; GARCíA SANZ, C. (1995) Huelva en época tartésica. Huelva: Diputación de Huelva, 1995

- RUIZ MATA, D. (1986) Aportación al análisis de los inicios de la presencia fenicia en Andalucía Sudoccidental según las excavaciones del Cabezo de San Pedro (Huelva), S. Bartolomé (Almonte, Huelva), Castillo de Doña Blanca (Puerto de Santa María, Cádiz) y El Carambolo (Camas, Sevilla). En Homenaje a Luis Siret (1934-1984). Sevilla: Consejería de Cultura, 1986, pp. 537-556

- RUIZ MATA, D. (1995) Las cerámicas del Bronce Final. Un soporte tipológico para delimitar el tiempo y el espacio tartésico. Tartessos 25 años después (1968-1993). Jerez de la Frontera: Ayuntamiento, 1995, pp. 265-313

- RUIZ MATA, D.; BLÁZQUEZ MARTÍNEZ, J. M.; MARTÍN DE LA CRUZ, J. C. (1981) Excavaciones en el Cabezo de San Pedro (Huelva). Campaña de 1978. Huelva Arqueológica, n. ${ }^{\circ}$ 5, 1981, pp. 149-316

- SCHUBART, H.; GARRIDO ROIZ, J. P. (1967) Probegrabung auf dem Cabezo de la Esperanza un Huelva. Madrider Mitteilungen, n. ${ }^{\circ} 8,1967$, pp. 123-158

- toscano, C.; CAMPOS, J. M. (2018) Elementos religiosos orientales en la Turdetania atlántica: ¿novedad o perduración del período orientalizante? Folia Phoenicia, n. ${ }^{\circ}$ 2, 2018, pp. 341-348

- VIDAL, N. O.; CAMPOS, J. M. (2006) Las necrópolis de Onuba. Anales de Arqueología Cordobesa, 17, vol. II, 2006, pp. 13-34

- VALLEJO SÁNCHEZ, J. I. (2010) Recipientes de bronce. En LÓPEZ, M. D.; GARCíA, E. (ed.) Cádiz y Huelva. Puertos Fenicios del Atlántico. Sevilla: Fundación Cajasol, Junta de Andalucía, 2010, pp. 310-311 